\title{
Development of High Ratio Coke Mixed Charging Technique to the Blast Furnace
}

\author{
Shiro WATAKABE, ${ }^{1)}$ Kanji TAKEDA, ${ }^{1)}$ Hirobumi NISHIMURA, ${ }^{2)}$ Shigeaki GOTO, ${ }^{3)}$ Nozomu NISHIMURA, \\ Tetsuro UCHIDA ${ }^{3)}$ and Mitsuru KIGUCHI ${ }^{3)}$
}

1) Steel Research Laboratory, JFE Steel Corporation, 1 Kokan-cho, Fukuyama, Hiroshima 721-8510 Japan.

2) East Japan Works, JFE Steel Corporation, 1-1 Ogishima, Kawasaki-ku, Kawasaki, Kanagawa 210-8510 Japan.

3) East Japan Works, JFE Steel Corporation, 1, Kawasaki-cho, Chuo-ku, Chiba 260-0835 Japan.

(Received on October 13, 2005; accepted on December 22, 2005)

\begin{abstract}
Technique for high ratio coke mixed charging was developed and applied at JFE Steel's East Japan Works (Chiba District) No. 6 blast furnace as the first case of application to a large blast furnace. Simultaneous discharging of ore and coke from the top bunkers, and the precise control of burden distribution technique with the mathematical model considering the segregation behabior of mixed layer have made it possible. Since April 2002, high productivity operation with the world's lowest level of sinter ratio has been conducted using high ratio coke mixed charging technique.
\end{abstract}

KEY WORDS: high ratio; coke mixed charging; blast furnace; bell-less charging; simultaneous discharging; burden distribution; permeability; cohesive zone; coke size; high productivity; sinter ratio; low RAR.

\section{Introduction}

Considering recent trends in the world economy and global environmental problems, ${ }^{1)}$ the key technical issues for blast furnace operation in Japan are now high productivity operation with the smallest possible number of blast furnaces, low reducing agent ratio (RAR) operation, low coke ratio operation, and greater freedom in the selection of ore materials, including low grade ores. Effective means of achieving these objectives are, use of high reducibility materials or high strength, high reactivity coke, improvement of gas utilization and reduction of heat loss by burden distribution control. ${ }^{2,3)}$

Deterioration of gas permeability or delay of reduction due to use of a high ore-to-coke ratio $(\mathrm{O} / \mathrm{C})$ must also be considered. Ore-coke mixed charging is known to be adequate to high $\mathrm{O} / \mathrm{C}$ operation, as it improves high temperature reducibility and gas permeability.

Among research in this connection, Hotta et al. studied the high temperature properties of thin ore and coke layers and of a uniform ore-coke mixing layer and found that gas permeability was improved in both cases. ${ }^{4)}$

Gono et al. studied the effects of mixing low quality ore with coke, ${ }^{5)}$ finding that the reducibility and high temperature properties of the raw material were improved by mixing with coke, and indicated that the optimum $\mathrm{O} / \mathrm{C}$ was 3-5. Application of mixed charging at Nagoya No. 3 blast furnace resulted in improvement of $\eta \mathrm{CO}$ by $0.4 \%$ and reduction of the fuel ratio by $3 \mathrm{~kg} / \mathrm{t}-$ pig.

Isobe et al. studied the permeability of the cohesive zone of the mixed layer quantitatively using an under-load-reduction test system. The results showed that, if the coke mixing ratio is less than $3 \mathrm{wt} \%$, pressure drop decreases as the coke mixing ratio increases, and the mixed coke reacts completely before flowing into the deadman. ${ }^{6}$

As these studies show mixing coke with ore improves blast furnace operation. However, only under-size coke (small coke) has been used commercially as the mixing coke, and the mixing ratio has been limited to less than $5 \mathrm{wt} \%$. These restrictions are adopted to prevent deterioration of permeability due to spread in the diameter distribution of the charged material. Furthermore, segregation in the mixed layer during dropping from the chute or at the stock surface, which is caused by differences in the diameter and/or density of the ore and coke is also a serious problem, ${ }^{7,8)}$ as this makes burden distribution control difficult, and the reacted coke or coke fine tends to concentrate in the deadman, which deteriorates gas and liquid permeability in the hearth. Therefore, small coke is generally mixed with the ore at the bin before conveying to the blast furnace top $^{9,10)}$ in order to prevent segregation of the mixed layer.

If the coke mixing ratio exceeds the amount of generation of small coke, the average diameter will increase significantly, causing marked segregation of the mixed layer. For this reason, with some exceptions, high ratio coke mixed charging has never been applied commercially. ${ }^{11,12)}$

Basic studies have been done to examine the segregation behavior of the ore-coke mixed layer with different particles. For example, Sunahara et al. quantified the segregation of two particles of different densities on a slope. ${ }^{13)}$ Calculating the mixed coke distribution for the bell top blast furnace, they showed that mixed small coke flowed to the furnace center when the stock was cone-shaped.

As seen above, the effects of coke mixing on gas perme- 
ability and high temperature properties, as well as segregation control techniques, should be studied considering the mixed coke size, such as lump coke or small coke when attempting industrial application. However, no study along these lines has yet been done, and the mixed coke ratio at large blast furnaces continues to limited to less than $5 \mathrm{wt} \%$.

The authors therefore studied the effects of the coke mixing ratio on gas permeability and high temperature properties at different sinter ratios and mixed coke sizes. The target burden distribution suitable for RAR operation and low sinter ratio operation was decided based on the results. Segregation of the mixed layer was also quantified by model experiments using a mathematical model. As a result, the authors developed a technique for high ratio coke mixed charging and applied this method at JFE Steel's East Japan Works (Chiba District) No. 6 blast furnace, which has a bell-less type charging system equipped with three parallel top bunkers, ${ }^{14)}$ as the first case of application to a large blast furnace. Since April 2002, high productivity operation with the world's lowest level of sinter ratio has been conducted using high ratio coke mixed charging technique.

\section{High Temperature Properties of Ore-Coke Mixed Layer}

\subsection{Experimental Procedure}

The effects of coke mixing on the high temperature properties of ore were investigated using the under-load-reduction test system ${ }^{15)}$ shown in Fig. 1. The under-load-reduction test system has a carbon heater which is separated from the reduction gas by a high-alumina tube. The crucible $(100 \mathrm{~mm} \Phi)$ is made of carbon and has carbon distributors at its top and bottom. The specimen is loaded by an automatic weighing system. Dripped metal and slag are collected at a water-cooled sampling plate below the furnace tube.

In this experiment, $\mathrm{CO}-\mathrm{CO}_{2}-\mathrm{N}_{2}$ mixed gas was introduced into the furnace tube while controlling the gas composition with an automatic controller. The flow rate was $5 \times 10^{-4} \mathrm{Nm}^{3} / \mathrm{s}$. Outlet gas collected from the furnace top was analyzed every $120 \mathrm{~s}$ by gas chromatography (device manufactured by Yanako). The gas composition was decided referring to measurements at the vertical sonde at Chiba No. 1 blast furnace. ${ }^{15)}$ The heating pattern, gas composi-

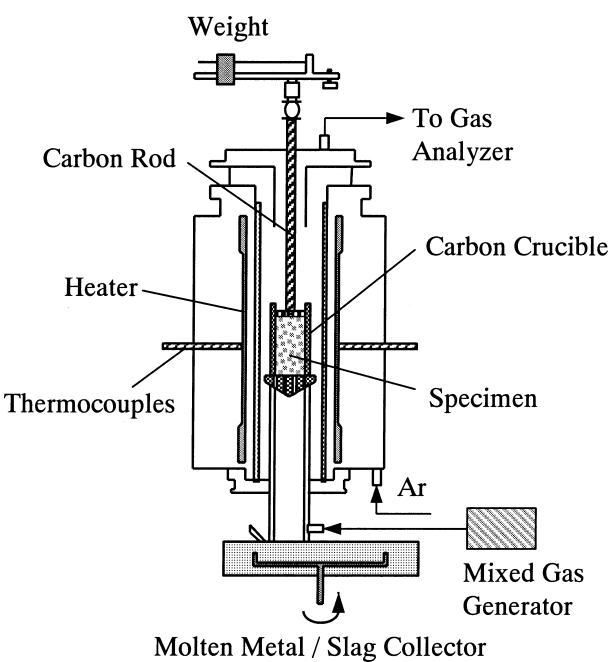

Fig. 1. Schematic view of under-load-reduction test system. tion, and the load were automatically controlled.

Material containing $0-20 \mathrm{wt} \%$ of mixed coke was tested. The amount of the ore was $900 \mathrm{~g}$, and the ore consisted of 100,75 , or $65 \mathrm{wt} \%$ sinter, with raw ore comprising the balance. This material was settled into the crucible with a 50 $80 \mathrm{~mm}$ height coke bed (15-25 $\mathrm{mm}$ coke diameter) by hand to ensure uniform distribution in the crucible. The particle size of the sinter and raw ore was $10-15 \mathrm{~mm}$, whereas that of the mixed coke was either 10-15 mm (small coke) or 30$40 \mathrm{~mm}$ (lump coke). The properties of the ore and mixed coke are shown in Table $\mathbf{1 .}$

\subsection{Experimental Results and Discussion}

The relationship between the mixed coke ratio and pressure drop during an under-load-reduction test with $100 \%$ sinter is shown in Fig. 2. Maximum pressure drop was distinctly lower with coke mixing, and also decreased as the mixing rate increased.

The effects of the coke mixing rate and sinter ratio on maximum pressure drop are shown in Fig. 3. With all sinter

Table 1. Properties of the ore and mixed coke used in experiments.

\begin{tabular}{|c|c|c|c|c|c|c|c|}
\hline & $\mathrm{t}-\mathrm{Fe}$ & $\mathrm{FeO}$ & $\mathrm{CaO}$ & $\mathrm{SiO}_{2}$ & $\mathrm{MgO}$ & $\mathrm{Al}_{2} \mathrm{O}_{3}$ & $S$ \\
\hline Sinter & 56.5 & 9.29 & 10.21 & 5.43 & 1.36 & 3.80 & 0.014 \\
\hline \multirow[t]{2}{*}{ Ore } & 64.1 & 0.14 & 0.43 & 3.32 & 0.03 & 0.94 & 0.008 \\
\hline & & FC & ash & $\mathrm{CaO}$ & $\mathrm{SiO}_{2}$ & \multirow[b]{2}{*}{ (wt $\%)$} & \\
\hline \multicolumn{2}{|c|}{ Mixed Coke } & 83.7 & 12.6 & 0.25 & 7.50 & & \\
\hline
\end{tabular}

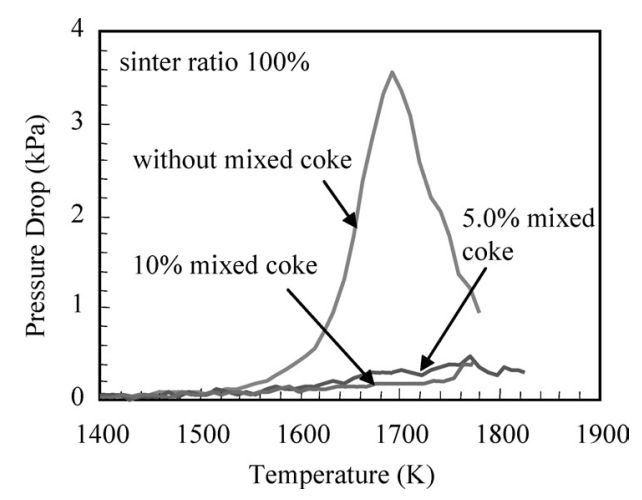

Fig. 2. Effects of mixed coke ratio on high temperature gas permeability of burden material (sinter ratio $75 \%$ ).

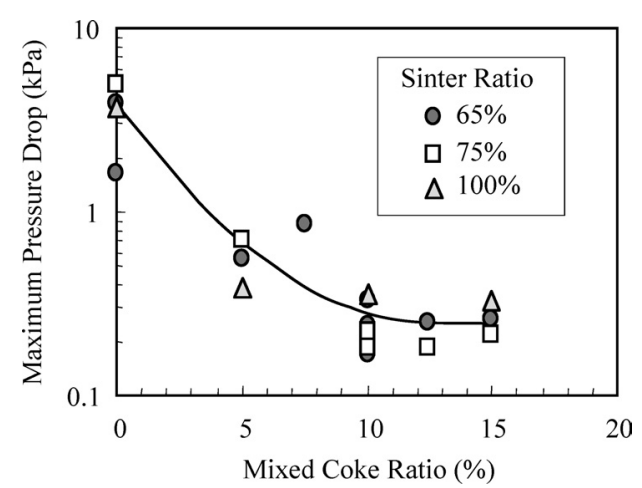

Fig. 3. Effects of mixed coke ratio and sinter ratio on high temperature gas permeability of burden material. 


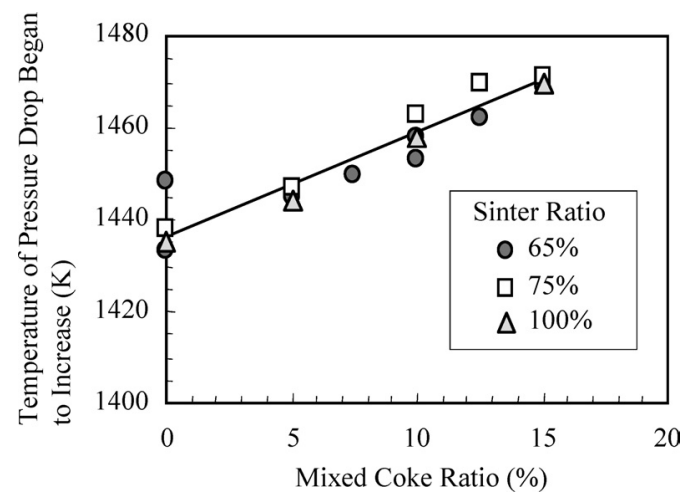

Fig. 4. Effects of mixed coke ratio and sinter ratio on the temperature of pressure drop began to increase.

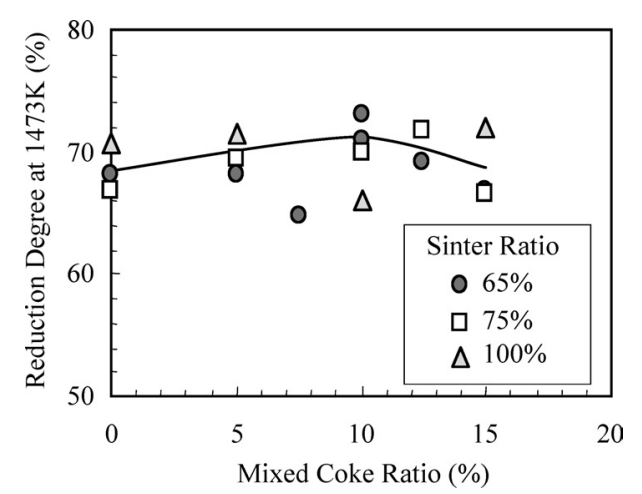

Fig. 5. Effects of mixed coke ratio and sinter ratio on the reduction degree at $1473 \mathrm{~K}$.

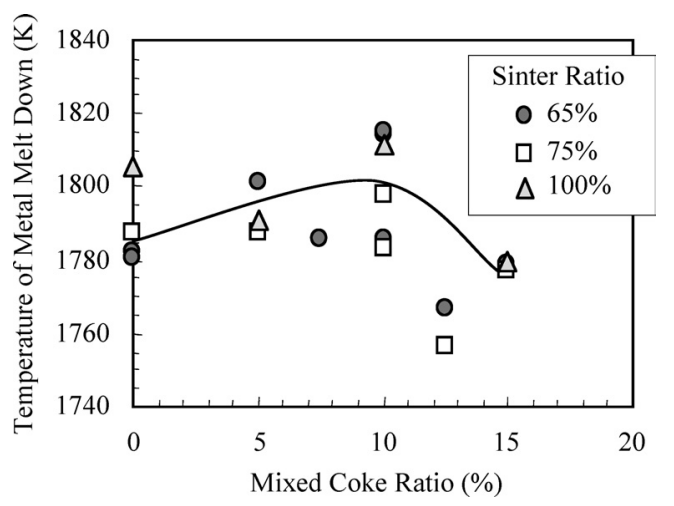

Fig. 6. Effects of the mixed coke ratio and the sinter ratio on the temperature of metal melt down.

ratios, the maximum pressure drop decreased - as the coke mixing rate increased up to $12.5 \mathrm{wt} \%$ but increased slightly when the mixing rate was $15 \mathrm{wt} \%$.

Figure 4 shows the change in temperature when the pressure drop began to increase, which became higher as the mixed coke ratio increased.

Figure 5 shows the relationship between the sinter ratio and the mixed coke ratio and changes in the reduction degree at $1473 \mathrm{~K}$. Reduction improved with the mixed coke ratio up to $10 \mathrm{wt} \%$. Figure 6 shows the effects of the mixed coke ratio and the sinter ratio on the temperature of metal melt down. The temperature of metal melt down showed a peak when the mixed coke ratio was $10 \mathrm{wt} \%$.

Next, the change in the maximum pressure drop and change in the reduction rate at $1473 \mathrm{~K}$ with large-diameter

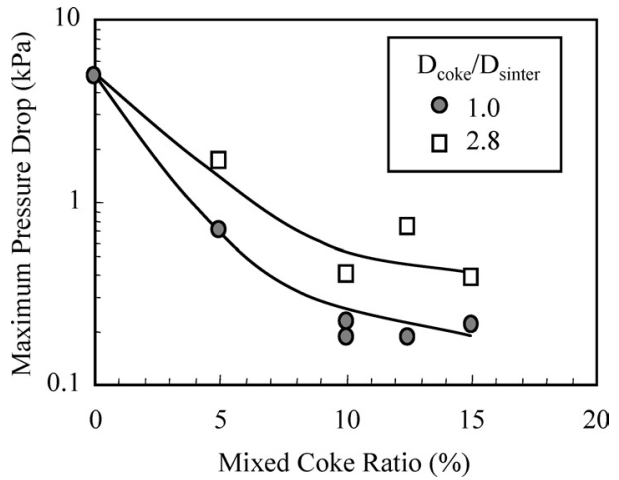

Fig. 7. Change in the maximum pressure drop at $1473 \mathrm{~K}$ with large-diameter mixed coke with a sinter ratio of $75 \%$.

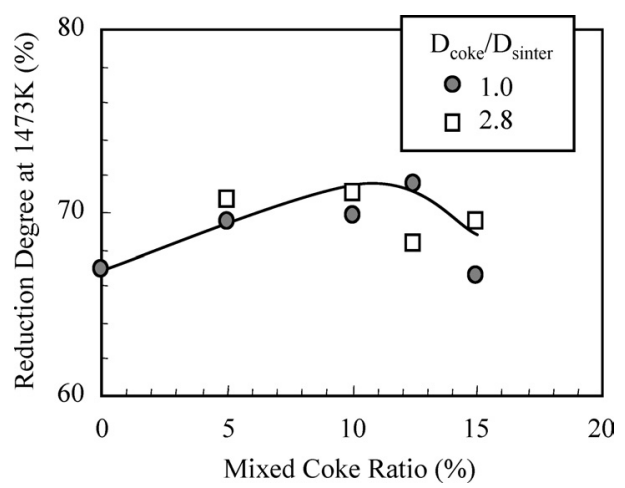

Fig. 8. Change in the reduction rate at $1473 \mathrm{~K}$ with large-diameter mixed coke with a sinter ratio of $75 \%$.

mixed coke with a sinter ratio of $75 \mathrm{wt} \%$ are shown in Figs. $\mathbf{7}$ and 8, respectively. These figures indicate that both gas permeability and reducibility also improve as a result of coke mixing when large-diameter coke is used in the mix.

The rate of indirect reduction by $\mathrm{CO}$ gas decreases due to the disturbance of the $\mathrm{CO}$ gas flow by the dense reduced product. In this study, pores were found around the mixed coke at the cross-section of specimens obtained during the under-load-reduction test. After carburization of the mixed coke around the reduced metal, the metal melted and pores formed. As reported by Hotta et al., ${ }^{4)}$ this is presumed to maintain the gas flow and to promote reduction in the high temperature range. Coke mixing also promotes the reduction of low reducibility materials such as raw ore, because the $\mathrm{FeO}$ in the slag can be reduced by the mixed coke.

Raw ore is known to have low temperatures for the start of softening and of for maximum pressure drop. ${ }^{5)}$ Coke mixing can raise these temperatures because the mixed coke reduces the $\mathrm{FeO}$ in the slag.

Bicknese et al. reported that the rate of $\mathrm{FeO}$ reduction by carbon was independent of the type of solid reductant under high $\mathrm{C} / \mathrm{FeO}$ ratio condition. ${ }^{16)}$ This can explain the reason why reducibility also improved when large-diameter coke was mixed.

As a conclusion from the under-load-reduction test experiments, the high temperature properties of ore are improved by coke mixing at ratios up to $10 \mathrm{wt} \%$. Considering the deviations which normally occur in commercial operation, the authors set the target mixing rate at $7.5 \mathrm{wt} \%$. 


\section{Study of Commercialization of High Ratio Coke Mixed Charging}

\subsection{Gas Permeability of Coke Mixed Bed}

The gas permeability of the coke mixed bed was measured using commercial sinter and coke. In this experiment, $100 \mathrm{~kg}$ of sinter (average diameter: $9.30 \mathrm{~mm}$ ) was packed in a cylinder with a diameter of $400 \mathrm{~mm}$ and uniformly mixed with lump coke (average size: $48.7 \mathrm{~mm}$ ) or small coke $(34.5 \mathrm{~mm})$. An air flow was introduced into the cylinder from the bottom at an empty cylinder velocity of $1-2 \mathrm{~m} / \mathrm{s}$, and the pressure drop was measured.

Figure 9 shows the effect of the diameter of the mixed coke on the gas permeability of the coke mixed bed. With both coke sizes (lump or small coke), pressure drop increased with the coke mixing ratio. When the coke mixing ratio was $15 \mathrm{wt} \%$, the increase in pressure drop was approximately $57 \%$ with the lump coke, and approximately $30 \%$ with the small coke. However, pressure drop did not increase above a coke mixing ratio of $15 \mathrm{wt} \%$.

\subsection{Gas Permeability of Cohesive Zone}

The decrease in the coke layer thickness (coke slit) must be considered in applying high ratio coke mixed charging to a commercial blast furnace when the coke ratio and coke base are kept constant, as a decrease in coke slit width may cause a deterioration of the gas permeability in the cohesive zone.

On the other hand, the gas permeability in the cohesive layer will be remarkably improved by coke mixing. Improvement of the cohesive layer permeability is expected to increase the gas flow at the cohesive layer, so improvement of the gas permeability of the cohesive zone is expected.

The authors attempted to evaluate this effect by calculation. Gas was assumed to be distributed so as to equalize the pressure drop along the cohesive layer and the coke layer in the cohesive zone. The gas resistance of the cohesive layer was calculated using Sugiyama's formula, ${ }^{17)}$ and that of the coke layer was calculated using Ergun's formula. ${ }^{18)}$

$$
\begin{gathered}
\frac{\Delta P}{L}=\left[\frac{1}{C m}\right]^{2}\left[\frac{1}{\Phi D_{\mathrm{p}}\left(1-S_{\mathrm{r}}\right)}\right]\left[\frac{\rho g u^{2}}{g D_{\mathrm{p}}}\right] \ldots \ldots . . . \\
\frac{\Delta P}{L}=150 \frac{u \mu}{g D_{\mathrm{p}}^{2}} \frac{(1-\varepsilon)^{2}}{\varepsilon^{3}}+1.75 \frac{\rho g u^{2}}{g D_{\mathrm{p}}} \frac{1-\varepsilon}{\varepsilon^{3}} .
\end{gathered}
$$

where $\Delta P$ is the differencial gas pressure, $L$ is the distance, $C$ is the discharge coefficient for orifice, $m$ is the diameter ratio, $\Phi$ is the average shape factor of particles in the mixed layer, $D_{\mathrm{p}}$ is the average diameter of particles, $S_{\mathrm{r}}$ is the contraction of particles, $\rho_{\mathrm{g}}$ is the density of gas, $u$ is the superficial velocity, $g$ is the gravitational acceleration, $M$ is the mixed coke ratio and $\varepsilon$ is the void fraction of packed bed. $D_{\mathrm{p}}$ and $\Phi$ were estimated from the cross-sectional observation of specimen of the suspended experiments.

Effects of the mixed coke ratio, mixed coke diameter ratio and the sinter ratio on the contraction of bed at $1573 \mathrm{~K}$ is shown in Fig. 10. From this results, $S_{\mathrm{r}}$ can be de-

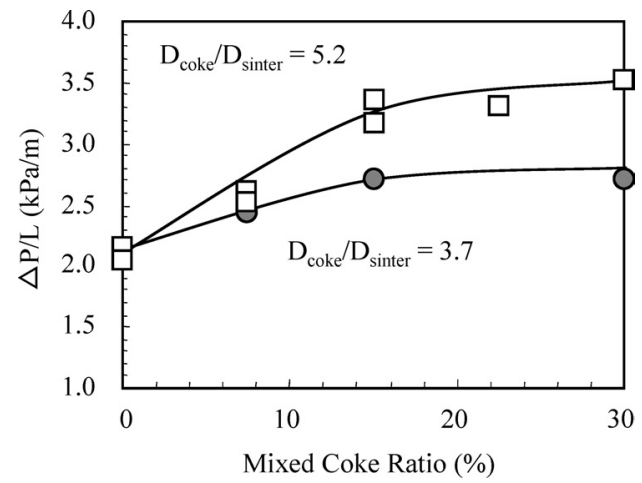

Fig. 9. Effect of the diameter of the mixed coke on the gas permeability of the coke mixed bed.

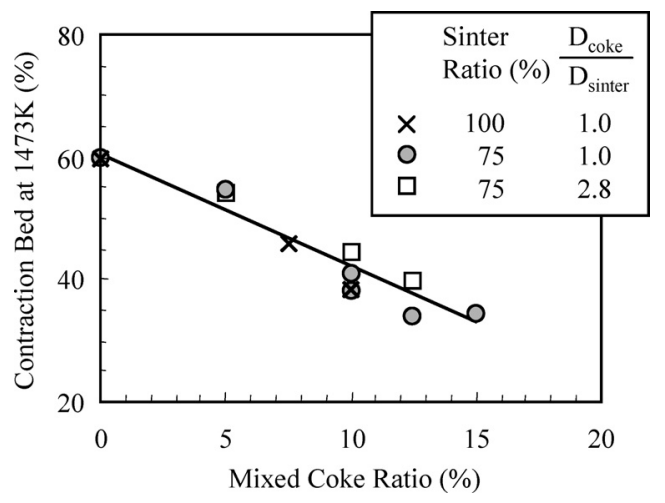

Fig. 10. Effects of the mixed coke ratio, mixed coke diameter ratio and the sinter ratio on the contraction of bed at $1573 \mathrm{~K}$.

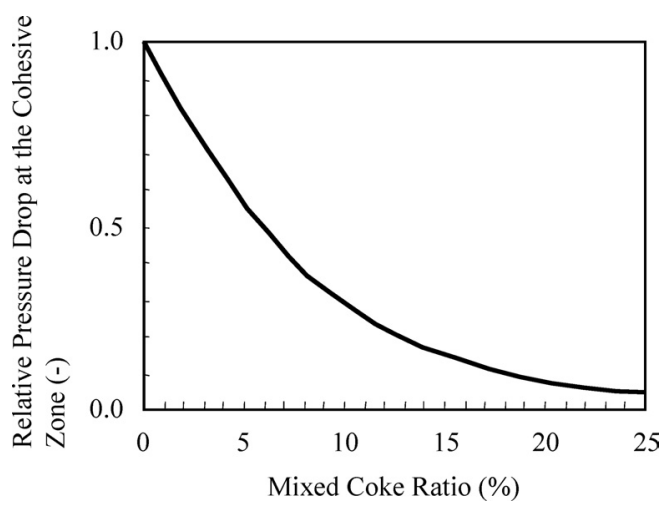

Fig. 11. Calculation result of change in pressure drop at the cohesive zone by coke mixing.

scribed as a function of the mixed coke ratio as shown below:

$$
S_{\mathrm{r}}=-1.88 M+61.3 .
$$

The void ratio of the mixing bed was calculated from the gas permeability measurement results. And the gas velocity and the number of cohesive layer was estimated assuming the cohesive zone forms a cone at the lower zone of the blast furnace. The shape of the cohesive zone and the gas volume were calculated using a 2-dimensional mathematical blast furnace simulator. ${ }^{19)}$

The calculation results are shown in Fig. 11. Total gas permeability is estimated to improve as the coke mixing ratio increases. 


\subsection{Evaluation of Change in Blast Furnace Operation by High Ratio Coke Mixed Charging}

The change in blast furnace operation by high ratio coke mixed charging was evaluated using the 2-dimensional blast furnace simulator. The baseline condition was that of Chiba No. 6 blast furnace in October 2002, productivity was 2.0, coke ratio was $387.5 \mathrm{~kg} / \mathrm{t}$-pig, PCR was $89.1 \mathrm{~kg} / \mathrm{t}$-pig, blast volume was $7780 \mathrm{Nm}^{3} / \mathrm{min}$ and oxygen enrichment was $1.4 \%$. Calculations were made for cases of sinter ratios of $72 \mathrm{wt} \%$ or $58 \mathrm{wt} \%$ with or without coke mixing. Contraction of the cohesive layer, the starting temperature of contraction, and the temperature of metal melt down were applied to the simulation model as functions of the coke mixing ratio based on the results of the experiments described above. The effect of the sinter ratio was given by a translation of the average RI value into the reduction rate parameter.

Figure 12 shows the calculation results. When the sinter ratio is decreased, reduction of the ore is delayed, the cohesive zone grows, and pressure drop increases. On the other hand, with coke mixing, the reduction rate increases, the width of the cohesive zone decreases, and the cohesive zone shifts upward. This is attributed to improvement of the gas permeability of the cohesive zone and a decrease in contraction of the cohesive layer. These results indicate that total pressure drop decreases due to coke mixing in the case of low sinter ratio operation.

\section{Development of High Ratio Coke Mixed Charging Technique}

\subsection{Experimental Procedure}

Segregation of the ore-coke mixed layer starts from the moment of mixing and is impossible to avoid during transportation to the blast furnace and charging from the top bunker. Consequently, the key points for establishing a high ratio coke mixed charging technique are (1) to position the mixing point as close to the charging point as possible and (2) to control the radial distribution of mixed coke ratio. For this purpose, the authors studied the discharge behavior of the mixed layer from the chute and segregation on the stock surface, and then applied the results to a mathematical model.

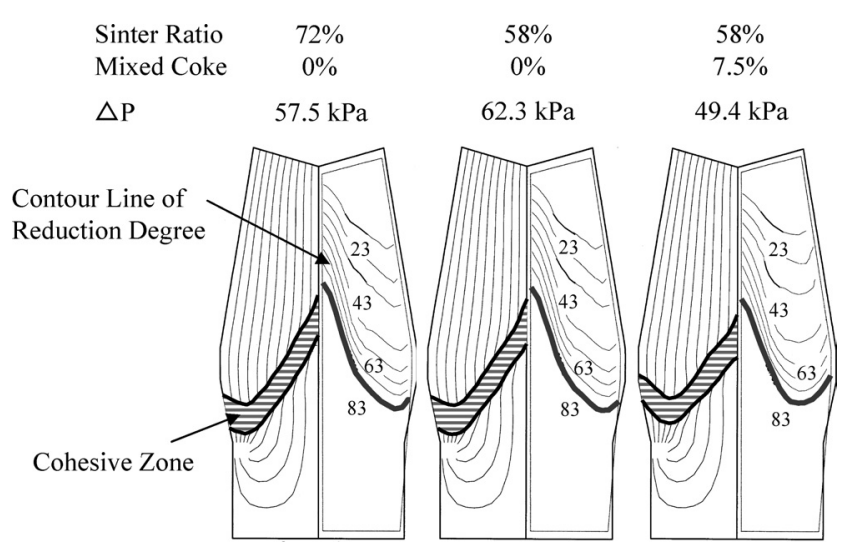

Fig. 12. 2-D BF simulation model calculation: change in cohesive zone and reduction degree in the blast furnace by the sinter ratio and coke mixing.
The experimental apparatus is a $1 / 17.8$ scale model of Chiba No. 6 blast furnace, which has a bell-less type charging system equipped with three parallel top bunkers. The apparatus is equipped with ore bins, a surge hopper, belt conveyers, and a charging system. The furnace body has 12 holes in the lower part for air blowing during charging.

The experimental conditions and size of the burden material were decided based on the scale factor of the experimental apparatus. ${ }^{20,21)}$ The ratio of inertia to gravity was set for the dropping material, and the ratio of internal friction to gravity and gas resistance to gravity were set for piling of the burden.

The coke mixing methods used in this experiment were 1) ore and coke were discharged simultaneously from each bin and mixed on the belt conveyer, 2) coke was discharged ahead of the bin, then ore was discharged and mixed at the belt conveyer, 3) ore was discharged ahead of the bin, then coke was discharged and mixed on the belt conveyer, and 4) ore and coke were discharged from the respective top bunkers and mixed on the charging chute. We call 1) "bin mixing discharge," 2) "coke-first discharge," 3) "ore-first discharge", and 4) "coke-ore simultaneous discharge." To measure the change in the burden material diameter, material was collected in a series of boxes moving on the belt conveyer. The effect of the stabilizer, ${ }^{14)}$ which is a charging flow control device on the tip of the chute, was also studied.

The segregation behavior of the mixed layer was studied by the following procedure. An ore-coke mixed layer was charged on the coke base with a slope of $30^{\circ}$ by ore-first or coke-first discharge, or by coke-ore simultaneous discharge. The amount of ore was equivalent to $120 \mathrm{t}$ in a commercial furnace. The tilting angles were 30, 40, 48 and $54.5^{\circ}$. The effects of the diameter ratio of the ore and mixed coke were studied.

The burden profile was measured by laser after charging, and the charged material was collected by inserting cylinders $50 \mathrm{~mm}$ in diameter into the burden surface to measure the radial mixing ratio.

The collected material and coke were screened after collection. The mixed layer was screened after separation. A gravity separation method using a sodium iodide solution, the specific gravity of which was adjusted to 1.95 , was used in this study. Separation accuracy was $98 \%$ or more.

\subsection{Experimental Results}

4.2.1. Change in Mixed Coke Ratio Charged from Chute

The change in the mixed coke ratio charged from the

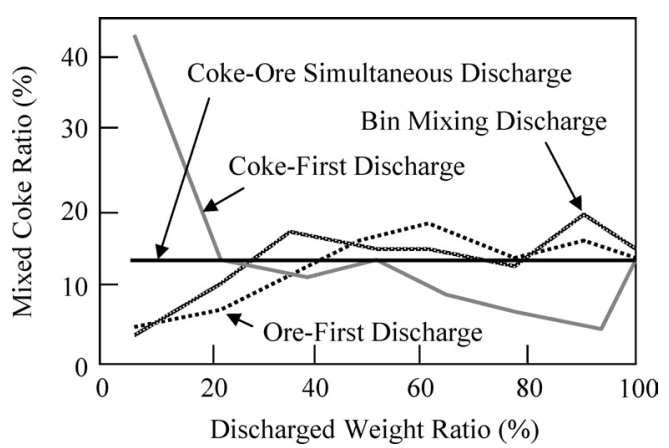

Fig. 13. Change in discharged mixed coke ratio by discharging method. 

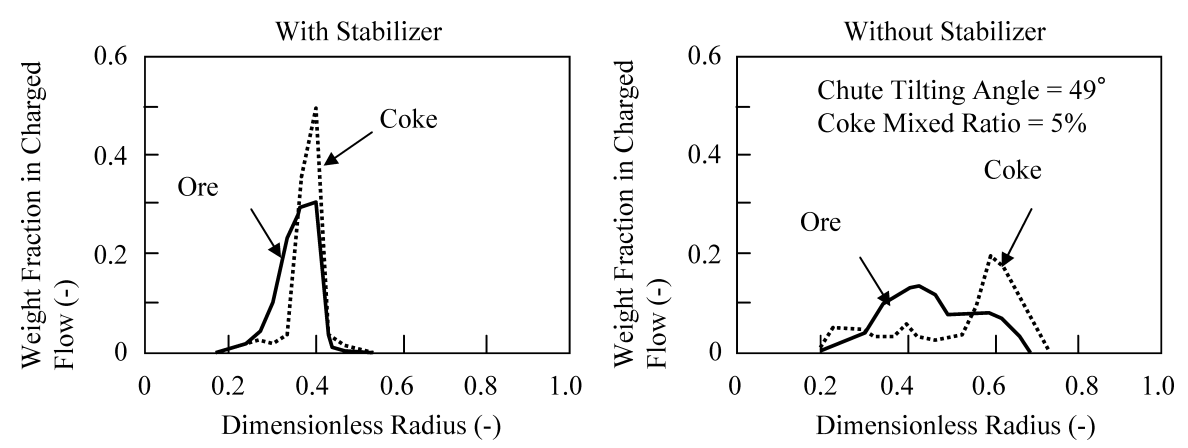

Fig. 14. Effects of the stabilizer on the dropping behavior of the discharged material.

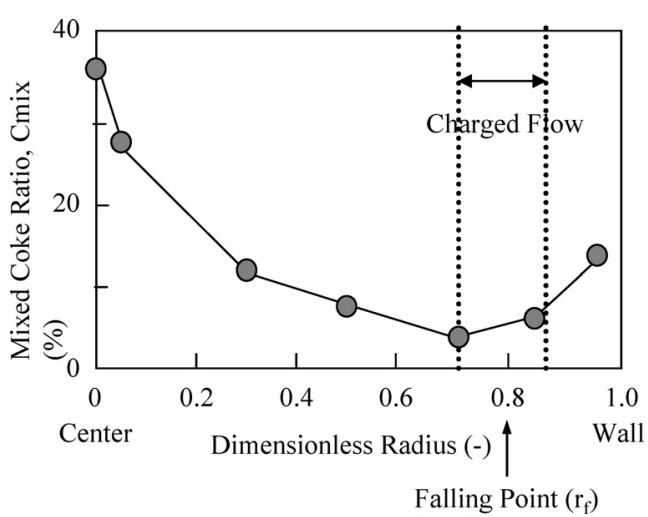

Fig. 15. Radial distribution of the mixed coke ratio in the burden (single-ring discharge, chute tilting angle $54.5^{\circ}$ ).

chute in the case where the total mixing ratio was $12.5 \mathrm{wt} \%$ is shown in Fig. 13. The amount of mixed coke at the beginning of charging was large with the coke-first discharge method, whereas the amount of ore was large with the orefirst method. With the bin mixing discharge method, the amount of ore was large at the beginning of charging, because the coke remained near the hopper wall while material was discharged by the funnel flow. The change in the mixed coke ratio showed a constant value with the coke-ore simultaneous discharge method.

Figure 14 shows the effects of the stabilizer on the dropping behavior of the discharged material with the coke-ore simultaneous discharge method when the mixing ratio was $5 \mathrm{wt} \%$ and the chute tilting angle was $49^{\circ}$. Without the stabilizer, the coke tended to segregate toward the wall, while the ore segregated toward the center. The mixed ore and coke are assumed to separate on the chute, with the coke tending to segregate upward, and the coke tends to have larger traveling speed due to lower friction with the chute. ${ }^{22)}$ With the stabilizer, the dropping points of the ore and mixed coke, coincided and the dropping width was sharper.

\subsubsection{Quantification of Segregation Behavior of Mixed Layer}

Figure 15 shows the radial distribution of the mixed coke ratio in the burden in the case of single-ring discharge with a chute tilting angle of $54.5^{\circ}$. The mixed coke ratio increased as the distance from the dropping point increased.

When a group of particles with a size distribution moves on a slope, the fine particles tend to remain at the upper region of the slope, while the coarse particles tend to move toward the base. This well-known phenomenon, which is

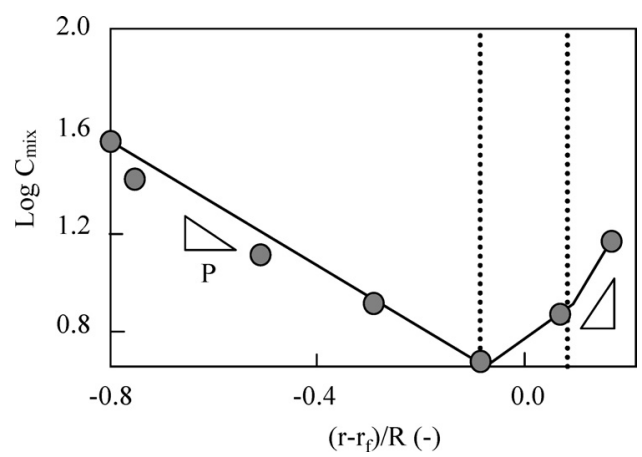

Fig. 16. Arranged result of Fig. 15.

termed percolation, is considered to be the result of the coarse particles acting as a screen. ${ }^{23)}$ Miwa et al. quantified this phenomenon in the following equation, ${ }^{24)}$ which shows that segregation increases with travel distance.

$$
\log X=a L+b
$$

Similarly, it is also known that a group of particles with a density distribution segregates during movement. ${ }^{25}$ ) As the above-mentioned segregation behavior is presumably applicable to the ore-coke mixed layer here, the experimental results were expressed in the equation shown below:

$$
\log \left(\frac{X}{1-X}\right)=P\left(\frac{r-r_{\mathrm{f}}}{R}+w\right)+C
$$

where $X$ is the mixed coke ratio, $P$ is a "segregation parameter" which explains the tendency of the mixed layer to segregate by the distance from the dropping point, $r, r_{\mathrm{f}}$ is the radius of falling point, $R$ is the radius of the furnace, $w$ is the dimensionless width of discharged flow and $C$ is logarithm of the mixed ratio at the dropping point. In all cases $w$ and $C$ resulted in constant values, 0.1 and 1.2 , respectively.

Using Eq. (5), Fig. 15 was arranged as shown in Fig. 16. A linear relationship was obtained in each region, demonstrating that the segregation behavior of the ore-coke mixed layer on the burden surface can be expressed by Eq. (5).

\subsubsection{Effects of Diameter Ratio and Charging Conditions on Segregation Behavior}

Figure 17 shows the effects of the diameter ratio and the charging rate on the segregation parameter, $\mathrm{P}$. The chute angles shown here are $54.5^{\circ}$ and $30.0^{\circ}$, and the ratio of the mixed coke diameter to the ore diameter are 3.6 and 7.3. 


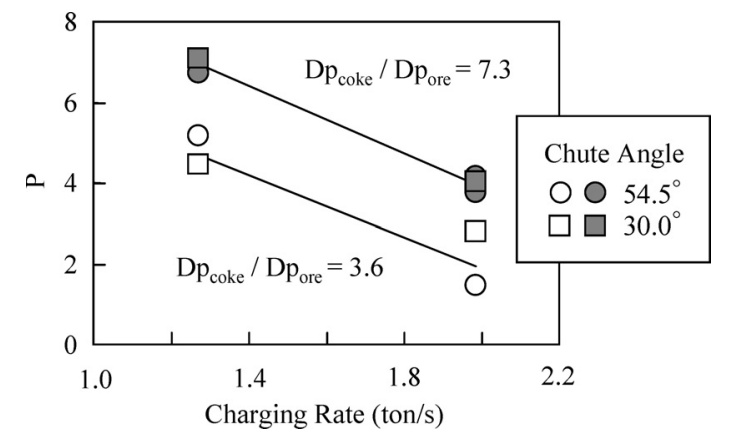

Fig. 17. Effects of the ratio of the mixed coke diameter to the ore diameter and the charging rate on the segregation parameter.

The charging rates as $0.96 \mathrm{~kg} / \mathrm{s}$ and $0.64 \mathrm{~kg} / \mathrm{s}$ corresponds to $1.27 \mathrm{t} / \mathrm{s}$ and $0.85 \mathrm{t} / \mathrm{s}$ in an actual blast furnace, respectively. The segregation parameter decreased as the charging rate increased and as the diameter ratio decreased. Observation of the burden surface after charging confirmed that the ore travel distance from the dropping point became larger than that of the coke as the charging rate increased.

\subsection{Development of High Ratio Coke Mixed Charging Technique}

\subsubsection{Mathematical Burden Distribution Model}

A mathematical burden distribution model which considers the segregation behavior of the ore-coke mixed layer was developed. The segregation parameter toward the wall or toward the center was evaluated as a function of the diameter ratio and charging conditions based on the experimental results, which was applied to the former model. ${ }^{26)}$ The development procedure was as follows:

(1) The mixed coke ratio in each chute rotation was calculated using the discharge experiment results.

(2) The dropping trajectory of the major stream of the mixed layer was calculated as the same as with ordinary ore.

(3) The radial distribution of the coke mixing ratio was calculated using the segregation parameter to match the mass balance.

(4) The burden profile was calculated.

Steps (3) and (4) were then repeated until the results agreed because the burden profile and segregation are interrelated.

(5) The radial distribution of mixed coke ratio in each rotation was totaled.

Comparison of the calculated and experimental results proved the accuracy of this model. Figure 18 shows a comparison for conventional tilting and reverse tilting. The results are in close agreement in both cases.

\subsubsection{Burden Distribution Control Procedure}

The pattern of burden distribution control to achieve a uniform mixed coke distribution layer was decided using the developed mathematical model. The charged ore and coke were divided into two batches each, and lump coke was mixed in the first ore batch and small coke was mixed in the second batch. The mixed lump coke was discharged simultaneously from the top banker, while the small coke was mixed on the belt conveyer after discharge from the

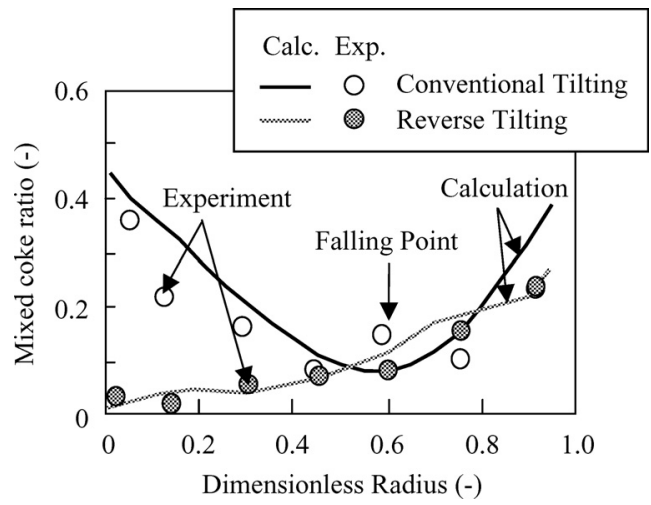

Fig. 18. Comparison of the calculated and experimental results for conventional tilting and reverse tilting.

bin. The total mixed coke ratio was $7.5 \mathrm{wt} \%, 3.75 \mathrm{wt} \%$ for each ore batch. The charging pattern was developed by mathematical model calculation.

A model experiment was carried out to examine the validity of the burden control pattern. After charging, low viscosity liquid resin was pored on the surface. After solidification, the sample was cut off to observe the cross section of the burden. A comparison of the results of high ratio coke mixed charging by the conventional method with the developed method is shown in Fig. 19. A uniform mixed coke layer can be achieved in the case of the developed method.

\section{Application of High Ratio Coke Mixed Charging to Commercial Blast Furnace}

\subsection{Application of High Ratio Coke Mixed Charging with Simultaneous Charging}

A charging pattern was developed for the radial distribution of Lo/(Lo+Lc) as shown in Fig. 20 (Lo is the thickness of the ore layer and Lc is that of the coke.) The ore batch composition, charging procedure, and mixed coke ratio are the same as those mentioned in Sec. 4.3.2. However, because increasing the number of charging batches limits productivity, the idea of feeding center coke and mixing lump coke in one batch was adopted. First, lump coke is charged from the coke bunker singly to the furnace center, then ore is charged simultaneously from the ore bunker and mixed with coke on the chute. This method makes it possible to feed a charge with a constant mixing ratio. The developed procedure is composed of three charging batches, the first batch being used to charge lump coke, the second batch to charge center coke and the ore-coke mixture, and the last batch to charge ore (mixed with small coke at the bin).

Before the application test at the actual blast furnace, the problems of the program sequence, time analysis of the entire charging system to achieve productivity over 2.5 , and the lower limit of coke and ore discharge from the top bunkers were studied.

\subsection{Application of High Ratio Coke Mixed Charging at Chiba No. 6 Blast Furnace}

High ratio coke mixed charging was applied to Chiba No. 6 blast furnace beginning on April 3, 2002. The basic 


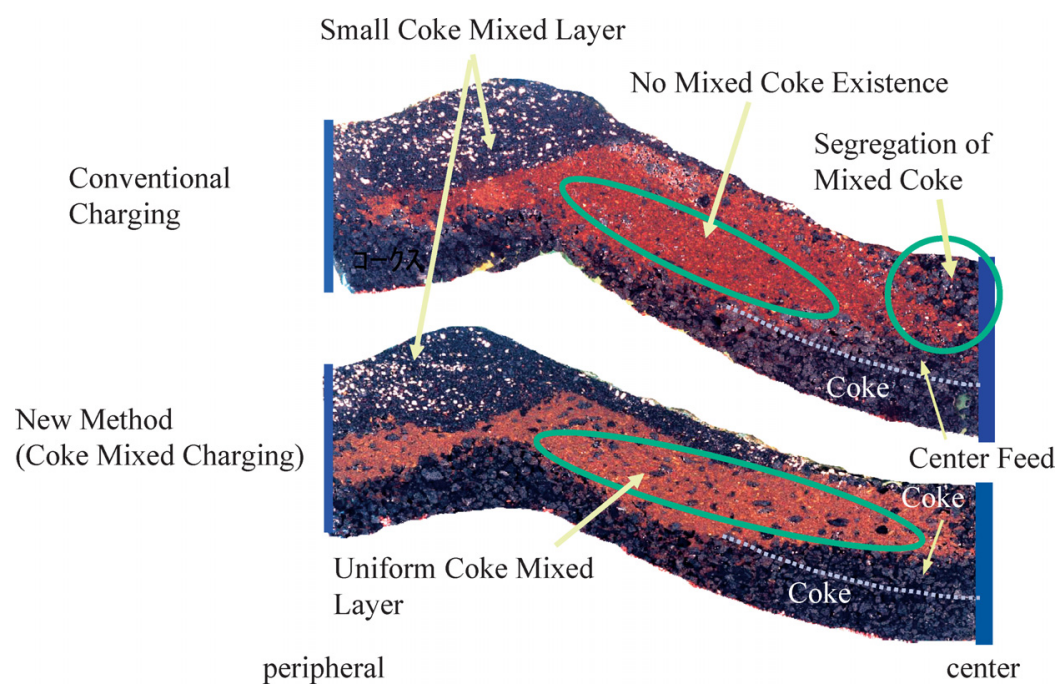

Fig. 19. Comparison of mixed coke distribution of high ratio coke mixed charging by the conventional method and the developed method (cross-section of burden model experiments).

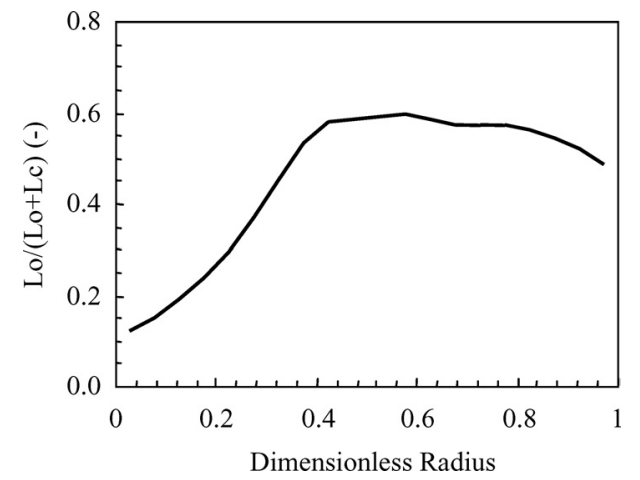

Fig. 20. Target radial distribution of $\mathrm{Lo} /(\mathrm{Lo}+\mathrm{Lc})$ for application of high ratio coke mixed charging to commercial blast furnace.

charging procedure was four batches, i.e., $\mathrm{C} 1, \mathrm{C} 2, \mathrm{O} 1, \mathrm{O} 2$. Small coke was mixed at a rate of $45 \mathrm{~kg} / \mathrm{t}$-pig in the $\mathrm{O} 2$ batch at ore bin's belt conveyer. In the first stage of the transition to ore-coke mixed charging, lump coke was mixed at a rate of $60 \mathrm{~kg} / \mathrm{t}$-pig in the $\mathrm{O} 1$ batch and small coke was mixed at $45 \mathrm{~kg} / \mathrm{t}$-pig in the $\mathrm{O} 2$ batch. The charging pattern was decided by mathematical model calculation. The amount of mixed coke was then increased to $120 \mathrm{~kg} / \mathrm{t}$-pig beginning on April 8.

The typical burden profile and gas utilization distribution obtained by the shaft gas sampler before (conventional) and after high ratio coke mixed charging operation are shown in Fig. 21. At the beginning of high ratio coke mixed charging operation, the blast pressure increased. The charged burden was unstable and the coke layer width around $r / R=0.2$ was thin with the early pattern. After adjusting the pattern to prevent ore from flowing to the center, the burden stabilized and gas utilization improved. On the other hand, the hearth temperature increased four weeks after the start of high ratio coke mixed charging.

The operational data were analyzed to study the effect of high ratio coke mixed charging. As shown in the Rist diagram in Fig. 22, shaft efficiency improved, and RAR decreased by approximately $10 \mathrm{~kg} / \mathrm{t}$-pig with high ratio coke mixed charging at a rate of $6.2 \mathrm{wt} \%$. Decrease in RAR can be explained by the decrease in the temperature of thermal

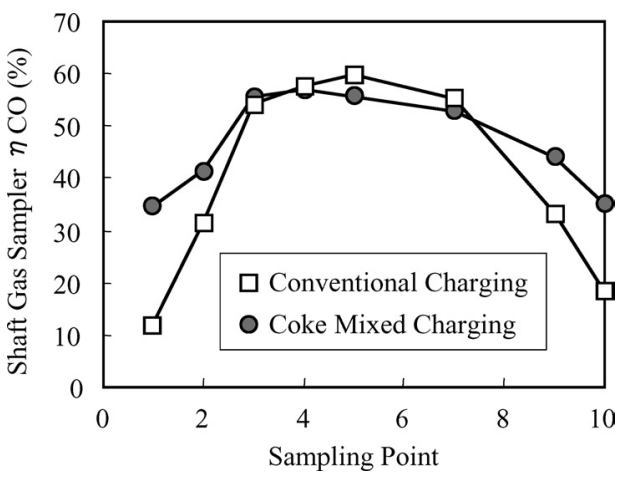

Fig. 21. Typical burden profile and gas utilization distribution obtained by the shaft gas sampler before and after high ratio coke mixed charging operation.

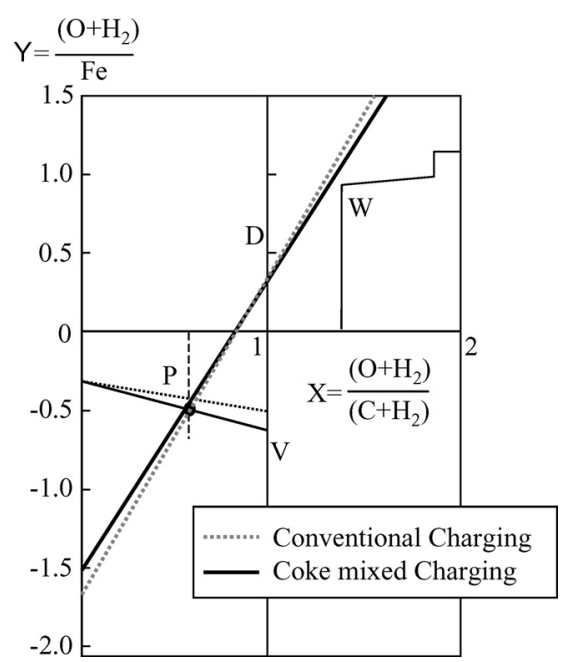

Fig. 22. Rist diagram for the Chiba No.6 blast furnace operations of conventional charging and coke-mixed charging.

reserve zone because of the high reactivity of mixed coke, ${ }^{27)}$ or improvement of gas permeability and heat conduction of the cohesive zone.

Figure 23 shows the change in the silicon content of the hot metal with a relation line of $0.004 \%$-Si $/ \mathrm{deg}$-HMT. The silicon content decreased by $0.15 \%$ with high ratio coke 
mixed charging. This can be explained by the fact that the level of the cohesive zone decreased because of the increase in the melt down temperature.

Ujisawa et al. pointed out that increase in coke reaction is concerned in low RAR operation using high reactivity coke. ${ }^{28)}$ In such case, coke fine in the deadman increases and void fraction of deadman decreases, which gives rise to poor slag drainage. ${ }^{29)}$ In the operation at Chiba No. 6 blast furnace, however, absolutely no decrease in the hearth temperature nor tapping problems were observed. Figure 24 shows the coke fine ratio in the deadman. Coke fine tended to decrease with high ratio coke mixed charging in comparison with conventional charging. A clean deadman was supposed to be achieved by the precise burden distribution control technique to prevent residual reacted mixed coke from flowing into the center.

Table 2 shows a comparison of the operational data for conventional charging (period A) and coke mixed charging (period B). The sinter ratio was $72.9 \mathrm{wt} \%$ during conventional charging and $74.1 \mathrm{wt} \%$ during coke mixed charging (no pellets were used). During period A, gas permeability was unstable in spite of pattern adjustment. Increases in the $\mathrm{FeO}$ content of the slag and $(\% \mathrm{MnO}) /[\% \mathrm{Mn}]$ were observed in this period. On the other hand, both the level and fluctuations of gas permeability in the lower part of the furnace improved remarkably during period B. Improvement of gas permeability resulted in decreases in RAR and heat loss and an increase in shaft efficiency.

As a conclusion, coke mixed charging has a great advantage in high productivity and low RAR operation under a

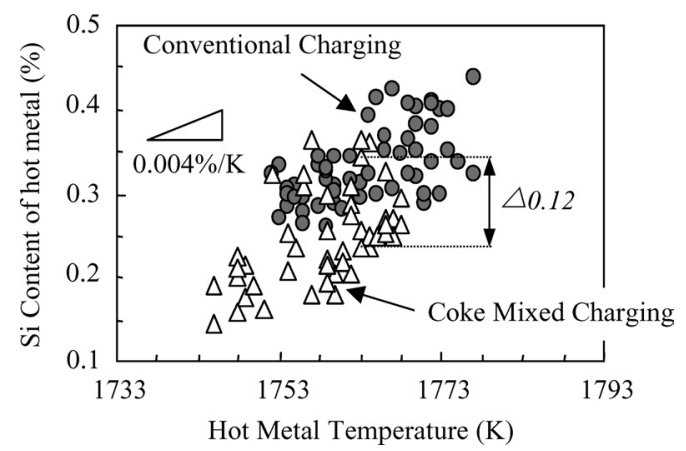

Fig. 23. Relationship between Si content and temperature of hot metal. low sinter ratio condition.

\subsection{High Productivity Operation by High Ratio Coke Mixed Charging at Chiba No. 6 Blast Furnace}

As mentioned above, blast furnace operation as a whole was improved. Before Chiba No. 5 blast furnace was blown off, a burden specification reduction test was performed, in which the sinter ratio (monthly average, no pellets were used) was reduced from $72 \mathrm{wt} \%$ in November 2002 to $56 \mathrm{wt} \%$ in March 2003 with some adjustment of the charging pattern. In this test period, productivity was $1.8-2.0$ and RAR was $500 \mathrm{~kg} / \mathrm{t}$-pig.

Productivity at Chiba No. 6 blast furnace was increased step by step after Chiba No. 5 blast furnace was blown off at June 2004. Because the capacity of the sinter plant at Chiba is less than that of the blast furnace, high productivity operation with a low sinter ratio was attempted.

RAR gradually decreased as gas utilization improved, and the target productivity of $12000 \mathrm{t}$-pig/d was achieved. Since that time, Chiba No. 6 blast furnace has remained in stable operation. The average data from April to June 2005 are productivity: $2.30 \mathrm{t}-\mathrm{pig} / \mathrm{m}^{3} / \mathrm{d}$, coke ratio: $397 \mathrm{~kg} / \mathrm{t}-\mathrm{pig}$, RAR: $498 \mathrm{~kg} / \mathrm{t}-\mathrm{pig}$, and sinter ratio: $74.1 \mathrm{wt} \%$.

\section{Conclusion}

High ratio coke mixed charging technique for the blast furnace was established and applied at JFE Steel's Chiba No. 6 blast furnace as the first case of application to a large blast furnace. As part of research for this purpose, underload-reduction tests and burden model experiments were

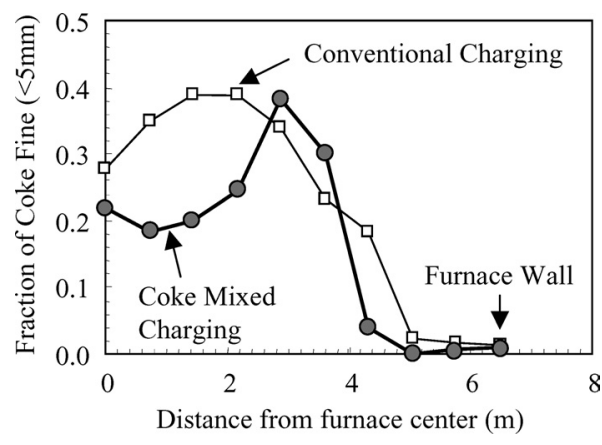

Fig. 24. Change in coke fine ratio in the deadman.

Table 2. Comparison of the operational data for conventional charging (period A) and coke mixed charging.

\begin{tabular}{|l|l||r|r|r|}
\hline & & $\begin{array}{c}\text { Conventional } \\
\text { ('04/4/6-5/8) } \\
\text { Period A }\end{array}$ & $\begin{array}{c}\text { Coke-Mixed } \\
\text { (5/10-6/21) } \\
\text { Period B }\end{array}$ & $\begin{array}{c}\text { After 5BF Blown } \\
\text { Off (7/1-11) }\end{array}$ \\
\hline \hline \multirow{5}{*}{ Operation } & Productivity (t/m $/$ /d) & 2.06 & 2.18 & 2.39 \\
& RAR (kg/t) & 517.8 & 495.8 & 495.7 \\
& CR (kg/t) & 412.4 & 396.1 & 395.1 \\
& Shaft Efficiency (\%) & 47.3 & 49.9 & 49.8 \\
& Gas Permeability Index & 87.5 & 91.0 & 90.4 \\
& Stave Heat Loss (GJ/hr) & 0.993 & 0.927 & 0.913 \\
& & 40.6 & 31.8 & 29.5 \\
\hline \multirow{5}{*}{ Burden } & Agglomerate Ratio (\%) & 72.9 & 74.1 & 74.7 \\
& No.4 Sinter Ratio (\%) & 49.4 & 45.4 & 39.5 \\
& Mixed-Coke Ratio (kg/t) & 60.0 & 109.0 & 116.3 \\
& Coke TI 400-6(\%) & 84.4 & 85.3 & 84.9 \\
\hline \multirow{3}{*}{ Tapping } & Si Content in Metal (\%) & 0.288 & 0.305 & 0.268 \\
& (MnO)/[Mn] & 1.31 & 1.13 & 1.17 \\
& Tapping (-/day) & 7.53 & 7.43 & 7.45 \\
\hline
\end{tabular}


conducted, and a mathematical model of the burden distribution was constructed based on the experimental results.

Since April 2002, high productivity operation with low sinter ratio has been conducted using high ratio coke mixed charging technique at Chiba No. 6 blast furnace.

(1) The reducibility of the ore and gas permeability in the cohesive zone were improved by coke mixing. The use of larger-sized coke in mixed charging has a slight effect on improvement of these characteristics.

(2) Ore-coke segregation behavior was formulated using Miwa's formula. A segregation parameter was defined as a function of factors such as the charging rate and diameter ratio of the coke and ore.

(3) Control of the charged ore-coke mixed layer by ore-coke simultaneous discharge method and use of the stabilizer, in combination with model calculations considering segregation of the ore-coke mixed layer, enabled precise control of the burden distribution to achieve a uniform mixed coke distribution and prevented movement of the mixed coke to the furnace center.

(4) The world's lowest level of sinter ratio, $56 \mathrm{wt} \%$ (monthly average, no pellets were used), was achieved at Chiba No. 6 blast furnace in March 2003 by applying the newly developed high ratio coke mixed charging.

\section{REFERENCES}

1) K. Nagano: Tetsu-to-Hagané, 90 (2004), 1.

2) M. Naito, Y. Hosoya, K. Yamaguchi, M. Higuchi, Y. Inoue and T. Haga: CAMP-ISIJ, 9 (1996), 627.

3) T. Sato, M. Sato, T. Ariyama, S. Watakabe and K. Takeda: CAMPISIJ, 17 (2004), 18.

4) H. Hotta, H. Yanaka, R. Yamamoto and S. Kishimoto: Tetsu-toHagané, 70 (1984), S814.

5) M. Gono, K. Iwatsuki, M. Takasaki, K. Nojima and T. Miwa: Tetsuto-Hagané, 68 (1982), S709.

6) M. Isobe, T. Sugiyama and S. Inaba: Prc. 6th Int. Iron Steel Cong.,
Vol. 2, ISIJ, Tokyo, (1990), 439.

7) H. Kokubu, M. Sato, Y. Konishi, S. Taguchi, S. Sakurai, K. Okumura and K. Ichifuji: Tetsu-to-Hagané, 70 (1984), S50.

8) R. Nakajima, T. Sumigama, A. Maki, K. Wakimoto and M. Sakurai: Tetsu-to-Hagané, 73 (1987), S3.

9) K. Okuda, K. Yamaguchi, N. Ishioka, T. Furukawa and H. Endo: Tetsu-to-Hagané, 70 (1984), S102.

10) K. Anan, T. Nagane, M. Nagata, M. Ogata, M. Honda and M. Isobe: CAMP-ISIJ, 12 (1999), 234.

11) T. Sato, T. Sumigama, A. Yamaguchi, K. Kimura, A. Shimomura and S. Furuya: Tetsu-to-Hagané, 70 (1984), S777.

12) Y. Nakagawa, T. Sawai and J. Hasegawa: Tetsu-to-Hagané, 78 (1992), S55.

13) K. Sunahara, C. Kajimoto, T. Inada: Proc. Ironmaking Conf., AIST, Warrendale, PA, (1999), 3.

14) T. Sato, T. Nouchi, K. Takeda and H. Kamano: Tetsu-to-Hagané, 86 (2000), 648

15) H. Kokubu, A. Sasaki, S. Taguchi and N. Tsuchiya: Tetsu-toHagané, 88 (1982), 2338.

16) E. Bicknese and R. Clark: Trans. Met. Soc., AIME, 236 (1966), 2.

17) T. Sugiyama, J. Yagi and Y. Omori: Tetsu-to-Hagané, 64 (1978), 1676.

18) S. Ergun: Chem. Eng. Progr., 48 (1952), 89.

19) T. Sato, T. Nouchi and M. Kiguchi: Kawasaki Steel Tech. Rep., 38 (1998), 24

20) S. Miyagawa, K. Takeda, S. Taguchi, T. Morimoto, M. Fujita and H. Fujimori: Kawasaki Steel Giho, 23 (1991), 130.

21) K. Konishi, S. Taguchi, T. Fukutake, K. Fukami, H. Itaya and Y. Serizawa: Kawasaki Steel Tech. Rep., 18 (1988), 16.

22) J. R. Johanson: Chem. Eng., May 8 (1978), 183.

23) K. Shinohara: Tetsu-to-Hagané, 81 (1995), 89.

24) S. Miwa: Huntai Kogaku Tshuron, Nikkan Kogyo Shinbunsya, Tokyo, (1981)

25) D. R. Michell: Trans. AIME., 130 (1938), 107.

26) T. Nouchi, T. Sato, S. Miyagawa, K. Takeda and H. Itaya: CAMPISIJ, 7 (1994), 1004.

27) M. Naito, K. Yamaguchi, H. Ueno and A. Okamoto Itaya: CAMPISIJ, 4 (1991), 1036.

28) Y. Ujisawa, K. Nakano, Y. Matsukura, K. Sunahara, S. Komatsu and T. Yamamoto: CAMP-ISIJ, 17 (2004), 6.

29) K. Nishioka, T. Maeda and M. Shimizu: ISIJ Int., 45 (2005), 1496. 